\title{
ANALISANDO CONHECIMENTOS E PRÁTICAS DE AGENTES EDUCACIONAIS E PROFESSORAS RELACIONADOS À ALIMENTAÇÃO INFANTIL
}

\section{Analyzing knowledge and practices of educational agents and teachers regarding to feeding children up to 3 years-old}

\author{
Andréia Cristina de Almeida Silva ${ }^{1}$ \\ Rodolpho Telarolli Júnior ${ }^{2}$ \\ Maria Iolanda Monteiro ${ }^{3}$
}

Resumo: Objetivou-se identificar os conhecimentos e as práticas relacionados à alimentação de crianças entre zero e três anos, a fim de complementar a formação das profissionais que trabalham com crianças, na área da educação nutricional. O procedimento metodológico seguiu as orientações do estudo de caso, com abordagem qualitativa. Os saberes e as práticas das participantes do estudo foram analisados por meio de questões abertas e fechadas e das observações dos tópicos relacionados à nutrição infantil, juntamente com os dados sobre a formação dessas profissionais. Pode-se concluir que tanto as agentes educacionais quanto as professoras de Ensino Infantil são detentoras de um conhecimento sobre Nutrição Infantil, porém a preocupação maior destas foi atender as necessidades nutricionais das crianças por meio de uma boa alimentação, deixando, em segundo plano, as atividades pedagógicas, as quais poderiam ser realizadas em um programa de educação nutricional, construído coletivamente e inserido no projeto político-pedagógico da escola.

Palavras-chave: Alimentação escolar. Educadores. Educação nutricional. Nutrição infantil. Pesquisa qualitativa.

\begin{abstract}
This study aimed to identify the knowledge and practices that people have regarding 0 to 3 year-old children in order to add information for professionals who work with this age group of children in the Nutrition Education field. The methodological procedure followed a case study, with a qualitative approach. The sample studied was analyzed through questions and observations of topics related to infantile nutrition along with data about these professionals' educational degrees. The results show that both, educational agents and infant education teachers have a significant knowledge about infant nutrition. However their biggest concern was to supply the children's nutritional necessities through a healthy meal, leaving in a second place the activities that could be accomplished by a Nutritional Education Program, built collectively and introduced into the school.
\end{abstract}

Keywords: Scholar nourishment. Educational agents. Nutritional education. Infantile nutrition. Qualitative research.

\footnotetext{
${ }^{1}$ Bacharel em Nutrição. Mestrado em Alimentos e Nutrição. Pesquisadora, Departamento de Alimentos e Nutrição, Faculdade de Ciências Farmacêuticas, Universidade Estadual Paulista (Unesp). Araraquara, SP, Brasil. $<$ andreias@gmail.com>

${ }^{2}$ Medicina. Livre Docente em Saúde Coletiva. Docente, Departamento de Ciências Biológicas, Faculdade de Ciências, Unesp. Araraquara, SP, Brasil. <rtjr@terra.com.br >

${ }^{3}$ Pedagogia. Pós-Doutorado em Educação. Professora convidada, Universidade Federal de São Carlos, SP, Brasil.<miolmonteiro@ig.com.br>
}

${ }^{1}$ Avenida Hassib Mofarrej, 1066

Nova Ourinhos - Ourinhos, SP

$19.900-000$ 
Silva, A. C. A.; Telarolli Júnior, R.; Monteiro, M. I.

\section{Introdução}

Segundo a Pesquisa Nacional de Demografia e Saúde da Criança e da Mulher (PNDS) 2006, as crianças brasileiras menores de cinco anos apresentaram uma queda importante na prevalência de desnutrição energético-proteica em todo o país. Entretanto, a prevalência dessas crianças com excesso de peso para altura é de 6,6\%, mostrando a exposição das crianças brasileiras ao risco da obesidade na infância. A pesquisa mostrou ainda que as deficiências de micronutrientes, especialmente a hipovitaminose A, a anemia ferropriva e os distúrbios por deficiência de iodo, continuam sendo alguns dos principais problemas de saúde (BRASIL, 2008b).

Para alguns autores, isto vem caracterizar a ingestão de alimentos altamente energéticos e pobres em nutrientes na dieta das crianças. Portanto, pode-se perceber que o consumo alimentar está relacionado à obesidade, não somente quanto ao volume da ingestão alimentar, como também à composição e qualidade da dieta (TRICHES e GIUGLIANI, 2005).

Tanto a desnutrição, como a obesidade, são expressões de erros alimentares e, segundo o Ministério da Saúde e da Educação, o combate à pobreza e à fome, além da promoção da alimentação saudável, deveriam ser articulados e implementados em conjunto para que estes problemas sejam solucionados. Por isso a necessidade de políticas públicas voltadas para a Educação Nutricional torna-se assim urgente, principalmente, na idade de crescimento e desenvolvimento (BRASIL, 2006b).

Por estar em desenvolvimento, toda criança é muito vulnerável em todos os aspectos: físico, intelectual, emocional e espiritual. Assim, se houver algum obstáculo, intrínseco ou extrínseco a ela, que prejudique o seu desenvolvimento, a continuidade desse processo poderá ser comprometida, temporária ou permanentemente (VERÍSSIMO e SIGAUD, 1996).

O momento da alimentação, como o primeiro alvo para regulação cultural, é de fundamental importância no processo de desenvolvimento infantil (PHILIPPI, CRUZ e COLUCCI, 2003). A comida está relacionada, também, com um significado social, pois, cada vez mais, a criança vai explorando o alimento, observa e sente as formas, as texturas, os sabores e os aromas. Aos poucos, vai se tornando mais ativa durante as refeições. Portanto, esta fase é um excelente momento para a formação de hábitos alimentares saudáveis que respeitem as características de cada criança (SEABRA e MOURA, 2005).

A criança inicia seu vínculo alimentar no seio da mãe. Em seguida, começa a receber outros alimentos presentes na mesa da família e, ao mesmo tempo, já é inserida nas instituições de Educação Infantil, onde aprende e adquire novos hábitos. Pode-se dizer, assim, que essas situações contribuem para a formação de um habitus alimentar. Portanto, é importante ressaltar que, de acordo com a contribuição teórica de Bourdieu (2004), o babitus alimentar pode ser formado pelo contexto em que a criança está inserida, desde o ambiente familiar ao institucional. E, segundo Marinho, Hamann e Lima (2007), esse processo inclui aspectos sociodemográficos, escolaridade, renda e local de moradia, além dos aspectos subjetivos e culturais envolvidos nesse processo.

Porém, como o presente trabalho pretendeu qualificar a Educação Nutricional exercida pelas profissionais que trabalham com a faixa etária de zero a três anos, e não verificar a qualidade da apropriação do habitus alimentar da criança no contexto familiar, levou-se em consideração, somente, o contexto institucional. 
Devido às suas necessidades biológicas, as crianças menores de cinco anos de idade merecem atenção especial, pois a má alimentação pode ter consequências futuras à saúde do indivíduo. Uma criança desnutrida ou obesa poderá se tornar um adulto obeso e com outros distúrbios nutricionais associados, como diabetes, hipertensão e hiperdislipidemias (WALZEM e MURANO, 2008). Segundo esses autores, o crescimento da obesidade e das hiperdislipidemias entre as crianças mostra a necessidade da atenção dos familiares e profissionais na área da saúde e da educação para a melhora da qualidade na alimentação dessa população. A alimentação é um dos fatores mais importantes, além de complexo, apresentando-se como o responsável pelo crescimento do indivíduo.

Portanto, é essencial que todos os profissionais que trabalham com crianças contribuam para o acesso à alimentação, em quantidade adequada, de boa qualidade, tanto no valor nutritivo como no aspecto de higiene (CRUZ, 2005). Ainda, segundo o Ministério da Saúde e da Educação, o conhecimento sobre a nutrição, por todos os profissionais que atuam no campo da alimentação infantil, parece ser essencial para a melhora do quadro do estado nutricional das crianças brasileiras, pois estes, além de contribuírem na formação do hábito alimentar das crianças, podem auxiliar os pais na realização de tal tarefa. Por isso, a alimentação, no ambiente escolar deve ter função pedagógica e estar inserida no contexto curricular (BRASIL, 2006b).

O Programa Nacional de Alimentação do Escolar (PNAE), implantado desde 1955, tem como objetivo atender as necessidades nutricionais dos alunos durante sua permanência em sala de aula, além de ser um programa de natureza pedagógica, incluindo a alimentação e nutrição no contexto escolar com a finalidade de promover a formação de hábitos alimentares saudáveis. Os conceitos sobre esses assuntos, segundo essa política, devem estar entre as práticas e atividades pedagógicas de toda instituição de Educação Infantil, respeitando o caráter lúdico, prazeroso das atividades, e o amplo atendimento às necessidades de ações planejadas, ora espontâneas, ora dirigidas (BRASIL, 2008a).

De acordo com Veiga, todo projeto político-pedagógico deve ser construído e vivenciado em todos os momentos, por todos os envolvidos com o processo educativo da escola, buscando organizar o trabalho pedagógico da escola na sua globalidade. Então, no momento da alimentação, deve ser estudado como a educação alimentar e nutricional será trabalhada, pois deve seguir as necessidades de cada população. Além disso, é preciso tempo para acompanhar e avaliar a ação do mesmo (VEIGA, 2007).

Segundo uma pesquisa realizada pelo Instituto Nacional de Estudos e Pesquisas Educacionais Anísio Teixeira (INEP, 2003), houve, nos últimos anos, uma grande melhora na formação dos profissionais que trabalham com a Educação Infantil. Reduziu-se o número de professores leigos atuando na Educação Infantil e no Ensino Fundamental e houve, também nesse período, um aumento significativo no percentual de docentes da Educação Básica com formação de nível superior. Mas, ainda, persiste a mentalidade de que creches e pré-escolas não necessitam de profissionais qualificados e bem remunerados, de serviços eficientes de supervisão, não requerem prédios e equipamentos adaptados às necessidades infantis, não precisam de livros nem de brinquedos, o que contrapõe a importância de um trabalho educativo responsável pela construção da identidade das crianças brasileiras (CAMPOS, FÜLGRAFF e WIGGERS, 2006).

As especificidades das crianças da faixa etária de zero a três anos podem estar sendo colocadas de lado, pelo não reconhecimento do educador de que seu trabalho constitui um 
Silva, A. C. A.; Telarolli Júnior, R.; Monteiro, M. I.

dos elementos fundantes do desenvolvimento infantil. A própria condição de inclusão da criança pequena é algo em construção (SOUZA, 2008). Portanto, aqui está a relevância de pesquisas que possam estar contribuindo com a promoção de um atendimento adequado para as crianças de zero a três anos, pois agravando ainda mais o quadro da formação dessas crianças, há uma escassez de pesquisas que abordam a problemática destas, em relação à nutrição e, em outras situações, devido à resistência que as pessoas têm de trabalhar nessa faixa etária (BOT'TARO e GIUGLIANI, 2008).

Aos profissionais de saúde cabe a socialização dos conhecimentos atuais sobre alimentação infantil adequada, visando promover o desenvolvimento da criança. O desafio desses profissionais é conseguir orientar efetivamente a população e, sobretudo, as mães e os educadores das crianças (MONTE e GIUGLIANI, 2004), pois, de acordo com Tardif (2002), os saberes profissionais são fundamentados nas experiências de formação, além das experiências cotidianas de vida e de trabalho.

Com isso, no presente trabalho, percebeu-se a necessidade de identificar quais são os conhecimentos e as práticas, relacionados à nutrição infantil, dos profissionais que trabalham diretamente na construção do hábito alimentar de crianças de zero a três anos. A partir disso, pretende-se complementar a formação das agentes educacionais e professoras de Ensino Infantil na área da educação nutricional, revisando as práticas alimentares adotadas, identificando os aspectos positivos e potencializando-os, a fim de melhorar o quadro nutricional da população, por meio da construção e incorporação de hábitos alimentares saudáveis das crianças.

\section{Metodologia}

Para atender os objetivos, o delineamento metodológico da pesquisa seguiu as orientações do estudo de caso (ANDRÉ, 2005), com abordagem qualitativa, desenvolvida durante o ano letivo de 2007. O estudo foi realizado em um Centro de Educação e Recreação - CER - do município de Araraquara, localizado no interior do estado de São Paulo, com cerca de 196 mil habitantes.

Participaram deste estudo oito profissionais que trabalhavam na faixa etária de zero a três anos. Entre estas, duas eram as professoras responsáveis pelas atividades pedagógicas e seis eram agentes educacionais, as quais eram responsáveis pelos cuidados diários das crianças, como banho, troca e alimentação, além do início de algumas atividades pedagógicas. Essas profissionais eram separadas nas classes: Berçário I, que atende crianças de zero a um ano e seis meses incompletos; Berçário II, crianças de um ano e seis meses a dois anos e três meses incompletos; Classe Intermediária I, crianças de dois anos e três meses a dois anos e sete meses; Classe Intermediária II, crianças de dois anos e oito meses a três anos.

Vale ressaltar que o desenvolvimento da pesquisa foi iniciado somente após a aprovação do Comitê de Ética em Pesquisa da Faculdade de Ciências Farmacêuticas do Campus de Araraquara da Unesp, garantindo a segurança das participantes e das próprias crianças, presentes no CER durante o estudo.

Primeiramente, na fase exploratória da pesquisa, foi realizado um levantamento de dados, por meio de uma pesquisa bibliográfica, utilizando-se livros, revistas científicas, dissertações de mestrado, teses de doutorado e banco de dados on-line. Durante esta fase, também foi 
desenvolvido um roteiro de entrevista, com questões abertas e fechadas, abordando a formação e o conhecimento das participantes em relação à alimentação das crianças de zero a três anos. Foram realizadas, ainda nessa fase, a pesquisa e análise documental, além de visitas regulares ao CER, para descrever: a estrutura do serviço, a organização, as dinâmicas de atendimento desenvolvidas no espaço escolar, sobretudo na área da nutrição, e as características da população referida, bem como as redes de relações que conformam o serviço de Educação Infantil. Um dos documentos analisados foi o projeto político-pedagógico da instituição, no qual o momento da refeição para todas as faixas etárias era descrito como uma oportunidade de aprendizagem sobre alimentação e nutrição, entretanto não fazia referência a nenhum programa de educação nutricional inserido neste projeto.

Para obter os resultados, o presente estudo analisou: a formação e experiência das participantes, as observações das práticas alimentares adotadas e os comentários realizados pelas mesmas diariamente, além das entrevistas sobre os conhecimentos em relação à nutrição. Por isso, foi necessário o agrupamento das participantes da pesquisa em agentes educacionais e professoras de Ensino Infantil, pois a própria formação destas não permitiria uma única análise. Para que as participantes tivessem sua identidade preservada, a pesquisadora tomou o cuidado de identificá-las com nomes fictícios.

As observações foram realizadas em todos os encontros com o grupo, durante o ano letivo de 2007. As informações foram registradas num "diário de campo", o qual, na concepção de Triviños (1995), contribui para orientar o registro de informações importantes para o desenvolvimento da pesquisa.

A pesquisadora caracterizou, primeiramente, a rotina do CER e, para descrevê-la, realizou suas observações no período de uma semana em cada sala - Berçários I e II e Classes Intermediárias I e II. Em seguida, centrou-se na sistematização do processo de alimentação por faixas etárias, observando as práticas alimentares nos momentos das refeições, como: horário, cardápio elaborado, preparações servidas, utensílios utilizados pelas crianças, distribuição, ordem para servir, local onde são realizadas as refeições e profissionais que acompanham as refeições. Esta etapa também foi realizada com a permanência da pesquisadora durante uma semana em cada sala, totalizando um mês de observação.

Somente após essas observações gerais em relação à alimentação das crianças e a análise dos subsídios do Referencial Curricular Nacional para Educação Infantil (BRASIL, 1998), das Diretrizes Curriculares para Educação Infantil (BRASIL, 1999) e dos guias alimentares infantis brasileiros (BRASIL, 2006a; PHILIPPI, CRUZ e COLUCCI, 2003), a pesquisadora pôde selecionar os seis tópicos de análise a serem observados. Estes compreendem o modo de oferecer a alimentação às crianças e as atividades de educação nutricional, realizadas pelas participantes: quantidade de alimentos, ritmos individuais, preferências pessoais, percepções das responsáveis pelas crianças, práticas incentivadoras e ações educativas.

Em seguida à finalização do trabalho de campo, realizou-se a entrevista semiestruturada, a qual combina perguntas fechadas e abertas (TRIVIÑOS, 1995). A elaboração das questões deste roteiro de entrevista procurou obter informações sobre a escolha e formação profissional, além do conhecimento sobre nutrição, adquirido durante a formação das participantes. 
Silva, A. C. A.; Telarolli Júnior, R.; Monteiro, M. I.

\section{Resultados e discussão}

Os saberes e práticas das agentes educacionais e professoras de Ensino Infantil do CER em estudo foram analisados com base nos resultados obtidos nas entrevistas realizadas e nas observações dos tópicos de análise, relacionados à nutrição infantil, levando em consideração os dados obtidos sobre a formação dessas profissionais.

As observações permitiram alcançar dimensões explicativas das praticas alimentares adotadas pelas participantes no cotidiano de seu trabalho. Estas serão discutidas a seguir, de acordo com os tópicos de análise.

\section{Tópicos de análise}

\section{Quantidade de alimentos}

Este tópico aborda os fatores que influenciaram a quantidade de alimentos ingerida pelas crianças de zero a três anos, durante os momentos das refeições oferecidas no CER em estudo. As necessidades energéticas de um ser humano saudável, de acordo com a Ingestão Dietética de Referência (DRI), dependem e variam conforme a idade, o sexo, o peso, a altura e o nível de atividade física diária do indivíduo (THE NATIONAL ACADEMIES, 2005). Por isso, é importante a individualidade da quantidade de nutrientes ingeridos. $\mathrm{Na}$ faixa etária entre zero e três anos, há necessidade de maior cuidado em relação à alimentação, especialmente, por estarem em desenvolvimento, além da incorporação de novos hábitos alimentares. Portanto, é essencial que os profissionais na área da Educação Infantil tenham conhecimento sobre estes fatores, para que possam atender melhor as exigências nutricionais de cada faixa etária (PHILIPPI, CRUZ e COLUCCI, 2003).

De acordo com o respectivo trabalho, as participantes respeitavam a quantidade de alimentos que as crianças desejassem ingerir, insistindo para que comessem um pouco mais, ao perceberem que não haviam comido muito, mas sem forçá-las, ou permitindo que comessem tudo, mesmo quando a quantidade parecia ser maior que a ingerida, normalmente. Os limites explicitados pelas crianças sempre foram muito bem percebidos, interpretados e respeitados pelas participantes, tais como: empurrar o prato para o centro da mesa, balançar a cabeça de um lado para o outro, não abrir a boca para receber o alimento ou, ainda, cuspi-lo.

Já a prática de dar a oportunidade para que as crianças escolham o que querem comer e quanto querem de cada alimento, foi observada, apenas, entre as crianças da Classe Intermediária II. Essa prática, além de estimular a independência da criança, evita o desperdício, pois as crianças, aos poucos, vão se conhecendo e desenvolvendo o autocontrole, em relação à fome e saciedade (PHILIPPI, CRUZ e COLUCCI, 2003).

\section{Ritmos individuais}

O tempo que cada indivíduo leva para realizar sua alimentação e os fatores que se relacionam com este são os assuntos abordados nesse tópico. De acordo com o Ministério da Saúde, cada indivíduo possui um ritmo para realizar sua refeição. Já as crianças, geralmente, levam mais tempo para realizar tal "tarefa", em comparação aos adultos, pois além de mais dispersas, não têm a mesma habilidade com os talheres e sentem necessidade de brincar e falar enquanto comem. Portanto, os profissionais responsáveis pela alimentação infantil devem pro- 
porcionar um ambiente tranquilo e adequado para oferecer a refeição, respeitar o ritmo individual de cada criança, além de impor limites para as atitudes das mesmas (BRASIL, 2006a).

Percebeu-se, assim, que as participantes do presente estudo acompanhavam o momento das refeições, permitindo que cada criança comesse no seu ritmo. Sempre era esperado que todas as crianças terminassem de comer para que fosse servida a sobremesa, ou para que se levantassem da mesa. Além disso, as crianças nunca eram forçadas a comerem os alimentos que não quisessem. Porém, as refeições eram realizadas em um ambiente agitado, e não eram permitidas brincadeiras e muita conversa à mesa, para que não demorassem muito na realização desta tarefa. Pediam para que elas comessem primeiro e que deixassem as brincadeiras e conversas para depois da refeição.

\section{Preferências pessoais}

Este tópico aborda a relação entre as preferências alimentares das crianças, agentes educacionais e professoras de Ensino Infantil na formação do hábito alimentar dessas crianças. É essencial, para garantir uma boa saúde, que o indivíduo tenha uma dieta nutricionalmente equilibrada, ingerindo todos os alimentos da pirâmide alimentar, nas proporções adequadas a sua faixa etária (PHILIPPI, CRUZ e COLUCCI, 2003). Entretanto, segundo o Ministério da Saúde, a criança pequena tende a rejeitar as primeiras ofertas do alimento, pois tudo é novo: o sabor, o aroma, a consistência e a colher. Algumas se adaptam facilmente, porém, outras, levam mais tempo (BRASIL, 2006a).

Entre as participantes do estudo, em todas as faixas etárias, foram observados frequentes comentários sobre a dificuldade, sobretudo, em alimentar as crianças que rejeitavam alguns alimentos. Mas, a insistência em oferecer algum alimento, rejeitado anteriormente, não foi observada entre algumas participantes, embora a maioria insistisse, pois estas consideravam que a criança não gostava de tal alimento, acreditando estar respeitando suas preferências pessoais. Nos registros das informações, não foi verificada nenhuma interferência, por parte das profissionais, em relação ao consumo dos alimentos que foram rejeitados pelas crianças.

\section{Percepções das responsáveis pelas crianças}

Este tópico apresenta as percepções das agentes educacionais e professoras de Ensino Infantil, em relação às manifestações e aos desejos das crianças, além das alterações no padrão alimentar das mesmas. A criança pequena ainda não verbaliza seus reais sentimentos, desejos e gostos, por isso o profissional que trabalha com Educação Infantil deve ter muita paciência, dedicação e atenção (AMORIN, 2005). Alguns autores defendem a ideia de que percepções sobre alterações no padrão alimentar de cada criança são essenciais no processo saúde-cuidado. Existem diversos fatores, os quais também foram identificados na presente pesquisa, que interferem no apetite, como sono, dor e agitação, e estes devem ser cuidadosamente identificados, para que a criança não sofra as consequências de uma má alimentação (PHILIPPI, CRUZ e COLUCCI, 2003). Os saberes oriundos das experiências cotidianas de vida, de formação e de trabalho, como foram percebidos também nos resultados, parecem constituir o alicerce da prática e da competência profissional e, por isso, estes saberes favorecem na relação entre o profissional responsável e a criança (TARDIF, 2002).

Portanto, torna-se imprescindível que os profissionais da Educação Infantil sejam aptos a desvendar as reações das crianças para saber o que realmente elas estão querendo 
Silva, A. C. A.; Telarolli Júnior, R.; Monteiro, M. I.

expressar. E, em geral, as participantes do estudo acompanhavam os momentos das refeições, dando muita atenção às manifestações das crianças, em relação ao interesse por algum alimento e às alterações no padrão alimentar.

\section{Práticas Incentivadoras}

Neste tópico foram discutidas as práticas de incentivo, para que as crianças comam ou experimentem novos alimentos, utilizadas pelas participantes da pesquisa. Segundo o Ministério da Saúde, a criança que come, desde cedo, frutas, verduras e legumes variados recebe maiores quantidades de vitaminas, minerais e fibras, além de adquirir hábitos alimentares saudáveis. Por isso, cabe à mãe ou ao responsável pelos cuidados da criança incentivar o consumo desses alimentos, a fim de formar um hábito saudável (BRASIL, 2006a).

As agentes educacionais e professoras de Ensino Infantil investigadas preocupavamse com a alimentação das crianças do CER, em relação à quantidade e à qualidade dos alimentos. Incentivavam e insistiam para que elas ingerissem, pelo menos, um pouco de cada alimento. Todas as participantes mantiveram o controle nos momentos das refeições, impondo sua autoridade, para que as crianças obedecessem e seguissem suas ordens, por meio de conversas. As crianças, às vezes, não obedeciam, então, estas profissionais ameaçavam retirar o alimento ou, ainda, retirá-las da mesa. Entretanto, essas práticas foram menos notadas entre as professoras, as quais demonstraram ter uma menor responsabilidade no momento das refeições, por estarem menos presente, durante a realização dessa tarefa, o que está em concordância com os achados do trabalho de Alves (2006).

\section{Ações educativas}

As ações educativas adotadas nos momentos das refeições pelas agentes educacionais e professoras de Educação Infantil do CER, em estudo, foram abordadas neste tópico. Estas compõem as atividades voltadas à educação nutricional institucionalizada. A alimentação, desde os primeiros meses de vida, parece ser essencial à socialização da criança e à sua inserção na cultura de seu povo, pois no momento da alimentação a criança entra em contato com um sistema de representações e práticas de sua cultura (SEABRA e MOURA, 2005). Este é um período em que a criança se encontra em desenvolvimento, sendo capaz de aprender e adaptar-se aos estímulos recebidos. Portanto, torna-se essencial, para uma boa formação, que ela cresça num ambiente incentivador, capaz de desenvolver suas habilidades físicas, motoras, psíquicas e sociais (ROSSETTTI-FERREIRA, 2003).

Assim como Holland (1999) e Davanço, Taddei e Gaglianone (2004) sugerem, em seus trabalhos, que os funcionários precisam estar sensibilizados e conscientes de seu papel de educadores, especialmente no horário das refeições, as atividades educativas - relacionadas aos conhecimentos sobre nutrição - adotadas pelas participantes do estudo no momento das refeições quase não foram observadas. Estas se resumiram na transferência de poucas informações sobre nutrição às crianças, por meio de músicas, relacionadas à alimentação, antes das refeições, e de explicações sobre as consequências da boa alimentação direcionadas ao aspecto físico. Entretanto, as ações educativas, relacionadas aos modos e comportamentos à mesa e à higiene foram frequentemente observadas entre as participantes, pois estas sempre exigiam que as crianças seguissem suas orientações. 
Analisando conhecimentos e práticas ...

\section{Entrevista semiestruturada}

Em relação aos resultados obtidos na entrevista semiestruturada, pode-se afirmar que a organização das questões abertas do roteiro de entrevista enfocou informações sobre a escolha da formação profissional, além do conhecimento sobre nutrição, adquirido durante a formação das participantes. Com isso, pretendeu-se caracterizar as agentes educacionais e professoras de Ensino Infantil, para aprofundar-se na compreensão deste grupo.

A respeito da formação das participantes, apenas uma concluiu somente o Ensino Fundamental. As demais concluíram o Ensino Médio e cinco o Ensino Superior. Todas manifestaram afinidade com as crianças ou identificação pelo ato de ensinar. Entretanto, apenas duas agentes educacionais e uma das professoras relataram terem obtido algum conhecimento sobre Nutrição, durante sua formação.

A pesquisadora elaborou as questões fechadas que compreendem assuntos relacionados à nutrição infantil. Estas receberam o subsídio do Referencial Curricular Nacional para Educação Infantil (BRASIL, 1998), do Guia Alimentar para crianças menores de dois anos (BRASIL, 2006a), da Pirâmide Alimentar Brasileira para crianças de dois a três anos (PHILIPPI, CRUZ e COLUCCI, 2003) e do Manual de Procedimentos do próprio CER. Vale ressaltar que estes guias alimentares específicos para crianças foram os únicos desenvolvidos no Brasil.

A Tabela 1 identifica o número de acertos das participantes da entrevista sobre os conhecimentos em relação à nutrição infantil.

Tabela 1. Descrição das respostas às questões do roteiro de entrevista II de todos os participantes da pesquisa ${ }^{1}$.

\begin{tabular}{|c|c|c|c|c|c|c|c|c|}
\hline Temática & Camila & Caroline & Fernanda & Lilian & Marina & Thaís & Tatiana & Vanessa \\
\hline 1. Leite materno & * & * & & * & & * & & * \\
\hline 2. Alimentação complementar & * & * & & & * & & * & \\
\hline 3. Horários das refeições & * & * & & & & & * & \\
\hline 4. Consistência das papas & & & * & * & & & & * \\
\hline 5. Quantidade consumida & * & * & & & * & & & \\
\hline 6. Alimentação variada & * & * & & * & & & & \\
\hline 7. Consumo de alimentos saudáveis & * & * & * & * & * & * & * & * \\
\hline 8. Consumo de alimentos industrializados & * & * & * & * & * & * & * & * \\
\hline 9. Preparo e oferta da alimentação & * & * & * & * & * & * & * & * \\
\hline 10. Alimentação da criança doente & * & * & & * & * & * & & * \\
\hline 11. Recusa de um alimento novo & * & * & * & * & * & * & * & * \\
\hline 12. Necessidades energéticas diárias & * & * & * & * & * & * & * & * \\
\hline Total de acertos & 11 & 11 & 6 & 9 & 8 & 7 & 7 & 8 \\
\hline
\end{tabular}

1 * representa os acertos das participantes em cada resposta; a ausência do sinal significa que a participante não obteve êxito na questão.

Foi verificado, no presente trabalho, que as questões mais específicas à alimentação das crianças entre zero e três anos foram aquelas nas quais as participantes obtiveram menos êxito. Características como duração da amamentação exclusiva e introdução, consistência, 
horários e quantidade da alimentação complementar parecem não pertencer aos conhecimentos dessas profissionais. Durante o estudo do tópico de análise "quantidade de alimentos" e nos resultados da quinta questão, pôde-se notar que as participantes não tinham noção exata da quantidade que cada criança deveria ingerir, bem como dos fatores que influenciam a necessidade de cada criança. Isto mostra, novamente, que um programa de capacitação, em relação à educação nutricional, deveria ser instituído para que estas profissionais possam atender as necessidades das crianças e transmitir informações sobre conceitos nutricionais, visando a mudança de concepção e atitude.

Nos resultados das questões que abordavam o assunto sobre práticas alimentares saudáveis foram encontrados os maiores números de acertos. Acredita-se que isso tenha ocorrido, porque estas informações encontram-se mais divulgadas pela publicidade e mídia. Entretanto, a pesquisa mostra que as participantes não vinculavam o conhecimento com as práticas adotadas no cotidiano. Estas se preocupavam apenas em fazer com que as crianças comessem, um pouco, de cada alimento oferecido no cardápio, sem fazer distinção entre as mesmas, como foi verificado no tópico de análise "quantidade de alimentos".

Verificou-se, ainda, que as participantes não transmitiam informações sobre nutrição e alimentação, o que foi registrado nos tópicos "práticas incentivadoras" e "ações educativas". De acordo com Boog et al. (2003), as mensagens transmitidas pela publicidade e mídia informam a população sobre alimentação saudável, mas, ainda, não há a conscientização para a mudança dos hábitos alimentares por parte desta. É necessário um trabalho educativo e contínuo para esse fim, pois a mudança de hábitos envolve outros fatores, como social, cultural e psicológico (MARINHO, HAMANN e LIMA, 2007).

Todas as participantes tiveram êxito na questão referente aos cuidados com a higiene. Entretanto, algumas comentaram com a pesquisadora que acharam exagerada a afirmação de que a diarréia poderia causar até a morte de crianças.

Outra questão que levantou alguma dúvida entre as participantes foi a questão sobre alimentação da criança doente. A maioria das agentes educacionais e professoras manifestou dúvida em relação ao aumento do gasto energético do organismo no estado patológico. Mas, ao se depararem com as alternativas, concluíram que a afirmação acima estava correta. Nas questões relacionadas à recusa de um alimento novo e às necessidades energéticas diárias, todas as participantes também acertaram.

Pode-se concluir que, em relação aos conhecimentos sobre a alimentação de crianças de zero a três anos, os maiores números de acertos foram encontrados entre as agentes educacionais, e não entre as professoras de Ensino Infantil, demonstrando que a formação dessas profissionais não influenciou nos resultados. Porém, as participantes que relataram terem obtido algum conhecimento sobre nutrição durante sua formação, também não foram as que alcançaram os melhores resultados nestas questões. Holland (1999) também descreve, em seu trabalho, sobre a falta de capacitação dos funcionários em relação à alimentação das crianças. Foi observado, em um estudo sobre conhecimentos a respeito da Nutrição, que os professores, expostos a um programa de educação nutricional, além de adquirirem mais conhecimento, em relação à nutrição, tornaram-se mais conscientes do seu papel na formação de hábitos alimentares no ambiente escolar, ao término do programa (DAVANÇO, TADDEI e GAGLIANONE, 2004). Isto pode comprovar que os conhecimentos adquiridos não estão sendo suficientes para o processo de capacitação desses profissionais na área da educação nutricional. 
Analisando conhecimentos e práticas ...

Com base na análise dos resultados, verificou-se que as agentes educacionais obtiveram os maiores números de acertos nas questões, por causa de sua maior intimidade com os momentos das refeições. Percebeu-se que as agentes educacionais convivem diariamente com as crianças e passam a maior parte do tempo com elas, por isso, possuem mais experiência nos momentos das refeições. Já as professoras são menos ativas nesta tarefa, pois acompanham as crianças durante um período, apenas. Assim como foi observado no tópico de análise "percepções das responsáveis pelas crianças", as agentes educacionais demonstraram ter uma grande afinidade, interpretando e distinguindo as manifestações, desejos e alteração no padrão alimentar das crianças. No tópico de análise "práticas incentivadoras", pode-se notar o maior envolvimento dessas profissionais, comparando suas práticas com as adotadas pelas professoras.

\section{Considerações finais}

O presente estudo pode concluir que as participantes da pesquisa são detentoras de um significativo conhecimento sobre nutrição infantil, independentemente de sua formação, pois os maiores números de acertos foram encontrados entre as agentes educacionais, as quais não têm Ensino Superior e apenas uma possui a graduação em pedagogia. As participantes que relataram terem obtido conhecimento sobre nutrição, durante sua formação, também não foram as que mais acertaram as questões fechadas, nem as que responderam as questões abertas com maior desenvoltura. Algumas colocações quanto a estas respostas são apresentadas a seguir:

"De 0 a 3 anos a gente contribui "em tudo". A parte da Educação Infantil é ampla e trabalha com a crianças desde andar, comer, dançar. Mexe com a parte motora e cognitiva das crianças" [...]"É uma alimentação mais natural possivel, simples e com os nutrientes adequados a faixa etária". (Marina)

"Seria possivel fazer uma salada de frutas comunitária para estimular o consumo das "frutas", além disso, poderia ser feito um teatro dos "legumes", sempre trabalhando com uma linguagem "bem" simples "e, aos poucos". Mas tem que ser sempre para que as crianças aprendam e assimilem". (Vanessa)

Os anos de experiência também não influenciaram na frequência de acertos, pois as profissionais com mais anos de experiência não foram as que obtiveram os melhores resultados. Entretanto, a faixa etária em que as participantes já tiveram contato interferiu nos resultados, visto que os maiores números de acertos encontram-se entre as agentes educacionais que trabalharam, exclusivamente, com a faixa etária pesquisada. Estas, além de trabalharem com crianças de zero a três anos, possuem maior intimidade nos momentos das refeições, pois acompanham, diariamente, todas as refeições das crianças, durante sua permanência no CER. Já as professoras acompanham-nas somente por um período, como foi registrado na observação da rotina e nas características gerais da alimentação das crianças.

No desenvolvimento das respostas às questões abertas do roteiro de entrevista, também não houve notável diferença entre as profissionais que relataram terem obtido algum 
conhecimento em nutrição, durante sua formação, e as que não obtiveram, exceto uma, a qual também está entre as que mais se destacaram nas respostas relacionadas às questões fechadas. Porém, as professoras tiveram melhores argumentos e desenvolvimento nos comentários sobre os projetos que poderiam ser realizados no CER, para se trabalhar a educação nutricional com as crianças.

No decorrer das entrevistas, alguns saberes a respeito da educação nutricional foram explicitados, os quais, muitas vezes, não foram aplicados no cotidiano por falta de incentivo e condições de trabalho por parte da instituição e descontentamento das mesmas.

De acordo com o que Tardif e Lessard (2002) verificaram, em seu estudo, a escolha pela carreira e a satisfação com o trabalho das agentes educacionais e professoras de Ensino Infantil, no presente estudo, parecem interferir nas práticas adotadas no cotidiano profissional. A afinidade com crianças parece estar relacionada com a atenção que estas profissionais têm sobre as manifestações, os desejos e as alterações no padrão alimentar das crianças. Porém, a insatisfação com a sobrecarga de trabalho, condições de trabalho e salário, parecem desanimá-las durante o cotidiano, deixando as atividades pedagógicas, possíveis de serem realizadas no CER, em segundo plano.

Em relação às práticas alimentares adotadas, pode-se perceber que o incentivo, tanto pelas agentes educacionais, quanto pelas professoras, resume-se mais ao consumo de alimentos das crianças, em relação à quantidade e variedade. As ações educativas são realizadas somente por algumas das participantes, em alguns dias da semana, e limitam-se a canções sobre nutrição, a comentários sobre o que são alguns alimentos do cardápio, a hábitos de higiene e a comportamentos à mesa. Há uma significativa preocupação em garantir uma boa alimentação para as crianças, mas o momento das refeições quase nunca é visto como possibilidade de intervenção educativa nutricional.

Essa verificação confirma o que muitos autores vêm relatando sobre a dissociação entre o cuidar e o educar por parte dos profissionais que trabalham na área da Educação Infantil (AMORIN, 2005). Holland (1999), desde a década de 1990, sugeriu em seu trabalho que os profissionais que trabalham nesta área deveriam ser capacitados para exercer a função pedagógica de educação nos horários das refeições e, ainda, que todos os funcionários deveriam ser conscientes de seu papel de educador, especialmente, nos horários das refeições. $\mathrm{O}$ próprio projeto político-pedagógico da instituição estudada faz referência ao momento da refeição como uma oportunidade para que as crianças aprendam sobre alimentação e nutrição, formando um hábito alimentar saudável. Entretanto, como foi verificado no estudo, as participantes não recebiam nenhum tipo de capacitação para realizar esse trabalho de educação nutricional junto às crianças.

Para Veiga (2007, p. 12-13), o projeto político-pedagógico da escola deve ser "construído e vivenciado em todos os momentos, pelas pessoas envolvidas com o processo educativo da escola". Por isso as autoras defendem a necessidade de se construir, coletivamente, um programa de educação nutricional, envolvendo a participação dos profissionais que trabalham com a Educação Infantil e, sobretudo, dos pais das crianças para educar seus próprios hábitos alimentares em casa. Desse modo, poderão seguir as orientações alimentares dos profissionais, possibilitando o desenvolvimento do habitus alimentar das crianças no meio familiar (BORDIEU, 2004). 
Analisando conhecimentos e práticas ...

A inserção da família neste processo, dando exemplo aos seus filhos de uma atitude consciente em relação à alimentação saudável, é fundamental para que as crianças incorporem hábitos saudáveis, pois, caso contrário, a criança provavelmente abandonará o que aprendeu no ambiente escolar para seguir os maus hábitos alimentares da família, ou os permitidos por esta. A grande influência exercida pela publicidade e pela mídia é outro fator a ser combatido pela família e por profissionais que atuem na Educação Infantil com este trabalho de educação nutricional (BOOG et al., 2003).

Para isso, as autoras, também defendem a ideia de que a educação nutricional deve estar presente no projeto político-pedagógico da escola. O programa de educação nutricional deve, ainda, estar inserido no projeto político-pedagógico de cada instituição de Educação Infantil, para que o momento da refeição deixe de ser apenas uma tarefa de atendimento às necessidades nutricionais dessas crianças, conscientizando todos os funcionários de sua função educativa, nos momentos das refeições. Este programa deve, ainda, seguir as necessidades de cada população a fim de corrigir os principais erros alimentares que possam trazer futuros problemas à saúde dessas crianças, e as atividades pedagógicas desenvolvidas devem estar de acordo com as especificidades de aprendizagem de cada faixa etária.

Contudo, a pesquisa pôde concluir que as participantes têm conhecimento sobre Nutrição Infantil e preocupam-se com a alimentação das crianças. Entretanto, entre as atividades voltadas para a educação nutricional institucionalizada, não foi desenvolvido quase nenhum trabalho, prejudicando a formação do habitus alimentar. Provavelmente, a precariedade de trabalho envolvendo a educação nutricional configurou-se por causa das condições de trabalho e da ausência de incentivos por parte das autoridades educacionais.

\section{Referências}

ALVES, R. C. P. Percepção de educadores e proposta institucional acerca dos cuidados infantis de saúde em creches. 2006. 95f. Dissertação (Mestrado em Enfermagem) - Escola de Enfermagem, Universidade de São Paulo, São Paulo, 2006.

AMORIN, E. Educar versus cuidar. In: UNESCO. O cotidiano no centro de educação infantil. Brasilia: Unesco, 2005. p. 11-16. (Série Fundo do Milênio para a Primeira Infância, v. 4).

ANDRÉ, M. E. D. A. Estudo de caso em pesquisa e avaliação educacional. Brasília: Líber, 2005. 
Silva, A. C. A.; Telarolli Júnior, R.; Monteiro, M. I.

BOOG, M. C. F. et al. Utilização de vídeo como estratégia de educação nutricional em adolescentes: "comer ... o fruto ou o produto?". Rev. Nutrição, Campinas, v. 16, n. 3, p. 281-293, 2003.

BOTTARO, S. M.; GIUGLIANI, E. R. J. Estudo exploratório sobre aleitamento materno entre escolares de quinta série do Ensino Fundamental. Cad. Saúde Pública, Rio de Janeiro, v. 24, n. 7, p. 1599-1608, 2008.

BOURDIEU, P. Razões práticas: sobre a teoria da ação. 5. ed. Campinas: Papirus, 2004.

BRASIL. Fundo Nacional de Desenvolvimento da Educação. Disponível em: < http:// www.fnde.gov.br/home/index.jsp?arquivo=alimentacao_escolar.html>. Acesso em: 15 set. 2008a.

Ministério da Saúde. Centro Brasileiro de Análise e Planejamento. PNDS 2006: pesquisa nacional de demografia e saúde da criança e da mulher. Brasília: Cebrap, 2008b. (Relatório final).

Ministério da Saúde. Secretaria da Política de Saúde. Organização Panamericana de Saúde Guia alimentar para crianças menores de dois anos. Brasilia: SPS, 2006a. (Série A, Normas e manuais técnicos).

. Ministério da Saúde e Ministério da Educação. Portaria Interministerial no 1010, de 8 de maio de 2006. Institui sobre as diretrizes para a promoção da alimentação saudável nas escolas de educação infantil, fundamental e nível médio das redes públicas e privadas em âmbito nacional. Brasília: Ministério da Saúde, 2006b.

. Ministério da Educação e do Desporto. Secretaria de Educação Fundamental. Referencial curricular nacional para a educação infantil. Brasília: MEC, 1998. 3. v.

Ministério da Educação e do Desporto. Parecer n. 022/98, de 17 de dezembro de 1998. Diário Oficial da República Federativa do Brasil, Brasília, DF, 23 mar. 1999. Seção I, p. 8.

CAMPOS, M. M.; FÜLGRAFF, J.; WIGGERS, V. A qualidade da educação infantil brasileira: alguns resultados de pesquisa. Cad. Pesquisa, São Paulo, v. 36, n. 127, p. 87-128, 2006.

CRUZ, H. Saúde da criança. In: UNESCO; BANCO MUNDIAL; FUNDAÇÃO MAURÍCIO SIROTSKY SOBRINHO. O cotidiano no centro de educação infantil. Brasília: Unesco, 2005. p. 31-50. (Série Fundo do Milênio para a Primeira Infância, v. 4).

DAVANÇO, G. M.; TADDEI, J. A. A. C.; GAGLIANONE, C. P. Conhecimentos, atitudes e práticas de professores de ciclo básico, expostos e não expostos a curso de educação nutricional. Rev. Nutrição, Campinas, v. 17, n. 2, p. 177-184, 2004.

HOLLAND, C. V. A creche e seu papel na formação de práticas alimentares. 1999. 73f. Dissertação (Mestrado em Nutrição Humana Aplicada) - Faculdade de Saúde Pública, Universidade de São Paulo, São Paulo, 1999. 
Analisando conhecimentos e práticas ...

INEP - INSTITUTO NACIONAL DE ESTUDOS E PESQUISAS EDUCACIONAIS ANÍSIO TEIXEIRA. Estatísticas dos professores no Brasil. Brasília: INEP, 2003.

MARINHO, M. C. S.; HAMANN, E. M.; LIMA, A. C. C. S. Práticas e mudanças no comportamento alimentar na população de Brasília, Distrito Federal, Brasil. Rev. Brasileira Saúde Materno Infantil, Recife, v. 7, n. 3, p. 251-261, 2007.

MONTE, C. M. G.; GIUGLIANI, E. R. G. Recomendações para alimentação complementar da criança em aleitamento materno. J. Pediatr., Rio de Janeiro, v. 80, n. 5, p. 131-141, 2004. (Suplemento).

PHILIPPI, S. T.; CRUZ, A. T. R.; COLUCCI, A. C. A. Pirâmide alimentar para crianças de dois a três anos. Rev. Nutrição, Campinas, v. 16, n. 1, p. 5-19, 2003.

ROSSETTI-FERREIRA, M. C. A necessária associação entre o educar e cuidar. Pátio: educação infantil, Porto Alegre, v. 1, n. 1, p. 10-12, 2003.

SEABRA, K. C.; MOURA, M. L. S. Alimentação no ambiente de creche como contexto de interação nos primeiros dois anos de um bebê. Psicol. Estudo, Maringá, v. 10, n. 1, p. $77-86,2005$.

SOUZA, N. N. Concepções de educadoras de creche sobre o desenvolvimento da criança na faixa etária de zero a três anos. 2008. 103 f. Dissertação (Mestrado em Educação) - Programa de Pós-Graduação em Educação, Universidade Federal do Paraná, Curitiba, 2008.

TARDIF, M. Saberes docentes e formação profissional. 3. ed. Petrópolis: Vozes, 2002.

TARDIF, M.; LESSARD, C. Le travail enseignant au quotidien: contribuition à l'étude du travail dans les métiers et les professions d'interactions humanies. In: TARDIF, M. Saberes docentes e formação profissional. 3. ed. Petrópolis: Vozes, 2002. p. 112-149.

THE NATIONAL ACADEMIES. Dietary references intake for energy, carbohydrate, fiber, fat, fatty acids, cholesterol, protein and amino acids (macronutrients): a report of the panel on macronutrients subcommittees on upper refence level of nutrients and interpretation and uses of dietary refences intakes, and the standing committee on the scientific evaluation of dietary refence intakes. Washington, DC: The National Academis Press, 2005. Disponível em: <http://www.nap.edu/catalog/10490.html>. Acesso em: 30 out. 2007.

TRICHES, R. M.; GIUGLIANI, E. R. J. Obesidade, práticas alimentares e conhecimentos de nutrição em escolares. Rev. Saúde Pública, São Paulo, v. 39, n. 4, p. 541-547, 2005.

TRIVIÑOS, A. N. S. Introdução à pesquisa em ciências sociais: a pesquisa qualitativa em educação. São Paulo: Atlas, 1995.

VEIGA, I. P. A. Projeto político-pedagógico da escola: uma construção coletiva. In: . (Org.). Projeto político-pedagógico da escola: uma construção possível. 23. ed.

Papirus: Campinas, 2007. p. 11-35. 
Silva, A. C. A.; Telarolli Júnior, R.; Monteiro, M. I.

VERÍSSIMO, M. Ó. R.; SIGAUD, C. H. S. O ser criança. In: SIGAUD, C. H. S. et al. (Orgs.). Enfermagem pediátrica: o cuidado de enfermagem à criança e ao adolescente. São Paulo: EPU, 1996. p. 11-14.

WALZEM, R. L.; MURANO, P. Societal aspects in the dietary management of childhood Hyperlipidemia. J. Clin. Lipidol, EUA, v. 2, n. 3, p. 156-161, 2008.

Artigo recebido em novembro de 2009 e aceito em março de 2010. 